\title{
EFFECT OF COLD-ROLLING ON MECHANICAL PROPERTIES OF HAYNES 25 COBALT-BASED SUPERALLOY
}

\author{
Padina Ajami Ghaleh Rashidi ${ }^{{ }^{*}}$, Hossein Arabi ${ }^{2}$, Seyed Mehdi Abbasi ${ }^{3}$ \\ ${ }^{1}$ MSc Graduate, School of Metallurgy and Materials Engineering, Iran \\ University of Science and Technology (IUST), Tehran, Iran \\ ${ }^{2}$ Center of Excellence for High Strength Alloys Technology (CEHSAT), School \\ of Metallurgy and Materials Engineering, Iran University of Science and \\ Technology (IUST), Tehran, Iran \\ ${ }^{3}$ Metallic Materials Research Center (MMRC-MA), Tehran, Iran
}

Received 09.01.2017

Accepted 20.03.2017

\begin{abstract}
Effect of cold-rolling and annealing time on the microstructure, hardness and the tensile properties of Haynes 25 superalloy at room-temperature and $760{ }^{\circ} \mathrm{C}$ were investigated in this research. Hot-rolled and solutionized alloy of Haynes 25 was subjected to cold-rolling with different amounts of reductions, i.e. $5 \%, 10 \%, 20 \%, 30 \%$ and $35 \%$. After that, all cold-rolled samples were annealed at $1230{ }^{\circ} \mathrm{C}$ for a period of time from 2 to $120 \mathrm{~min}$. Microstructural analysis showed that for annealing time range from 30 to $120 \mathrm{~min}$, the rate of grains coarsening remained approximately stable in all cold-rolled samples. On the other hand, the hardness results showed that expected decreasing trend of hardness did not occur after annealing of the cold-rolled samples at $1230^{\circ} \mathrm{C}$; on the contrary, hardness increased moderately in the range time from 10 to $120 \mathrm{~min}$. Tensile properties after annealing of the cold-rolled samples at room temperature and $760{ }^{\circ} \mathrm{C}$ decreased. Loss of the tensile properties can be related to the high annealing temperature. According to the experimental results, decreasing trend of tensile properties and increasing trend of hardness is linked to the formation of hcp phase after annealing at $1230{ }^{\circ} \mathrm{C}$ for $30 \mathrm{~min}$. Even though the hcp phase is a hard phase, the interface between fcc and hcp phases provides suitable sites for crack nucleation and propagation.
\end{abstract}

Keywords: Cold-rolling; Haynes 25 superalloy; tensile properties; annealing; hcp phase.

\footnotetext{
* Corresponding author: Padina Ajami Ghaleh Rashidi, ajami@alumni.iust.ac.ir
} 


\section{Introduction}

Haynes alloy No.25 is a wrought, cobalt-based superalloy with a nominal chemical composition (wt.\%) Co-10Ni-20Cr-15W. This alloy maintains excellent hightemperature strength, good ductility and oxidation resistance up to $1093{ }^{\circ} \mathrm{C}$. Some examples of its applications include: gas turbine engines, wear pads, blades, and etc. $[1,2]$. Haynes 25 is typically solution treated between $1175^{\circ} \mathrm{C}$ and $1230{ }^{\circ} \mathrm{C}$ followed by rapid cooling to form a single-phase, face-centered cubic (FCC) structure. The fcc phase is metastable so that carbides and other phases can precipitate more straightforward after mechanical working and intermediate temperature annealing. The strength and hardening behavior of this alloy have been attributed largely to solid solution effects and carbides $[3,4]$.

Heat treating at temperature below $800{ }^{\circ} \mathrm{C}$ for prolonged time stimulates a loss of room temperature ductility in much the same as some other solid-solution-strengthened super alloys, such as Hastelloy X or Inconel 625 [5]. This behavior occurs as a consequence of the precipitation of deleterious phases. In the case of Haynes 25 alloy, this detrimental phase is $\mathrm{Co}_{2} \mathrm{~W}$ laves phase [5].

Haynes 25 exhibits excellent ductility and strong work hardening enabling either hot and cold working possible. At room temperature, this type of alloy possesses a high degree of strength and demonstrates a low degree of ductility due to cold-work dislocations storage [3,5]. It should be noted that due to rapid work hardening, machining of this alloy requires more power compared to the plain carbon steels. Traditional machining methods and tooling, such as carbide tools or high-speed steel tools, can be used for Haynes 25. However, it is not suitable to use carbide tools while milling, drilling or tapping. In these cases, it is better to use only high-speed steel tools [6].

Haynes 25 is a low stacking fault energy (SFE) alloy so that stacking faults (SFEs) are ordinarily observed in both deformed and undeformed material $[4,5]$. The low SFE makes cross-slip and dislocation climb difficult; therefore, alloy deforms by planar glide and SFEs are the predominant defects in the microstructure [3]. Commonly, cold working is followed by annealing process which results in recrystallization. Controlling the grains size distribution during recrystallization can lead to a significant improvement in the mechanical properties: in one hand, fine grains enhance the alloy strength; on the other hand, large grains provide more ductility to avoid rupture over service [7].

Koizumi et al. [8] and Tawancy et al. [9] have reported, it is highly likely that the transformation of fcc to hep happens in alloys with low stacking fault energy. According to these findings, there is a strong likelihood that the stacking faults on every $\{111\}$ atomic planes of $\gamma$-fcc will be transformed to $\{0001\}$ plane of the $\varepsilon$-hcp phase; by changing the stacking sequence on the $\{111\}$ planes of fcc phase from ...ABCABC... type to ...ABAB ... type related to $\{0001\}$ planes of hep phase. This phenomenon is called strain-induced martensitic transformation (SIMT) which largely has been observed in fec metals with very low FSEs, such as cobalt-based superalloys [8].

The mechanical properties of alloys are affected by strain-induced martensitic transformation of the fcc phase [7]. Based on the research which was conducted by Lee et al. [7], this phenomenon has a destructive influence on the tensile properties of alloys because of crack nucleation and propagation along the interface between the $\gamma$-fcc phase and the $\varepsilon$-hcp phase during tensile deformation. 
In this paper, we reported the experimental results on Haynes 25 in the solutiontreated condition in the temperature range where $\mathrm{Co}_{2} \mathrm{~W}$ laves phase and carbides, such as $\mathrm{M}_{7} \mathrm{C}_{3}$ and $\mathrm{M}_{23} \mathrm{C}_{6}$, do not form. The present investigation was carried out to measure the tensile properties of Haynes 25 alloy with emphasis on the role of cold working. Samples were cold reduced to various thicknesses and annealed at $1230{ }^{\circ} \mathrm{C}$. The effect of cold working on the mechanical properties, including yield strength, ultimate tensile strength and total elongation, was determined from tensile tests at room temperature and $760{ }^{\circ} \mathrm{C}$. Additionally, the effect of cold rolling and annealing time on the microstructure and hardness was studied to a certain extent.

\section{Materials and Methods}

A slab of Haynes 25 superalloy was produced using vacuum induction melting (VIM) furnace for casting and electro-slag remelting (ESR) technique for refining the alloy; the refined slab was hot rolled to the thickness of $16 \mathrm{~mm}$ at the temperature of $1200{ }^{\circ} \mathrm{C}$ and then was heat treated at $1230{ }^{\circ} \mathrm{C}$ for 1 hour.

With the aim of studding the effect of deformation on microstructure and mechanical properties, Haynes 25 superalloy was deformed by rolling to different thickness reductions $(0,5,10,20,30$ and $35 \%)$ at room temperature. After cold rolling (CR), specimens were annealed at $1230{ }^{\circ} \mathrm{C}$ for various times from 2 to $120 \mathrm{~min}$ and then were cooled in air.

The microstructure of the specimens was characterized by optical microscopy $(\mathrm{OM})$. Metallographic samples were ground after mounting by emery papers and then polished and etched in the mixture of $30 \mathrm{ml} \mathrm{HCl}, 7 \mathrm{ml} \mathrm{H}_{2} \mathrm{O}$ and $3 \mathrm{ml} \mathrm{H}_{2} \mathrm{O}_{2}$.

Hardness was measured with Koopa UV1 (Universal Hardness Tester) under a load of $30 \mathrm{kgf}$. At least three indentations were made for each hardness measurement and the average hardness was reported.

The mechanical properties of the cold-rolled specimens were then measured by tensile test before and after annealing at $1230{ }^{\circ} \mathrm{C}$ for $30 \mathrm{~min}$. The flat specimens were prepared for tensile testing at room temperature and $760{ }^{\circ} \mathrm{C}$, according to ASTM E-8M and E-21 standards, with the tensile axis parallel to the rolling direction. All the tensile tests were carried out at a strain rate of $7 \times 10^{-7} \mathrm{~min}^{-1}$. The total elongation was determined by measuring the distance, before and after testing, between fiducial marks which were lightly scribed on the samples gauge lengths. Tensile tests were performed on a computer controlling universal tensile test system.

\section{Results and discussion}

\section{Microstructure of Haynes 25 superalloy}

The typical micrographs of Haynes 25 superalloy, after $10 \%$ and $30 \%$ cold rolling and annealing at $1230{ }^{\circ} \mathrm{C}$, were presented in Fig. 1. As shown, by increasing the percentage of cold rolling a lower initial time was needed to finish the recrystallization process. Dark areas in Fig. 1a and 1b, exhibit slip bands, directional accumulation of dislocations in highly packed slip planes, which emerged after etching are evidence for zones not recrystallized.

An increase in annealing time from 20 to 30 min resulted in grain coarsening in $30 \%$ cold-rolled sample. However, in $10 \%$ cold-rolled specimen, as it can be seen in 
Fig. 1a and $1 \mathrm{~b}$, in spite of providing enough time for grain growth the average grain size decreased from $130 \mu \mathrm{m}$ to $87 \mu \mathrm{m}$.

Variation of the average grain size for all cold-rolled samples after annealing at $1230{ }^{\circ} \mathrm{C}$ was indicated in Fig. 2. This figure shows that there is a drop in the grain size of $10 \%$ cold-rolled specimen when annealing time increased from 20 to $30 \mathrm{~min}$; this is in agreement with Fig. 1a and 1b. Also for the annealing time spectrum of 30 to 120 min, the rate of grain coarsening is crudely leveled out in all cold-rolled samples.

This decrease in grain size and a significant low pace of grain growth can be explained in terms of Zener pinning of grain boundaries [10]. According to this mechanism, hard particles, such as carbides, which have not been identified with conventional methods in this study, limit grain boundaries migration. When a boundary passes through an incoherent particle the portion of boundary that is inside the particle essentially stops to exist and in order to move on some new boundaries must be created. This is energetically unfavorable so that the region of boundary near the particle is pinned [10]. In this way, the grain growth is limited over annealing and the average grain size cannot increase significantly.

A natural trend of grain growth is observed in the microstructure of the samples which were cold rolled more than $10 \%$ (i.e. $20 \%, 30 \%$ and $35 \%$ ). It should be noted that in specimens with the higher percentage of cold working may very fine particles formed that were not able to prevent grain boundary movement.
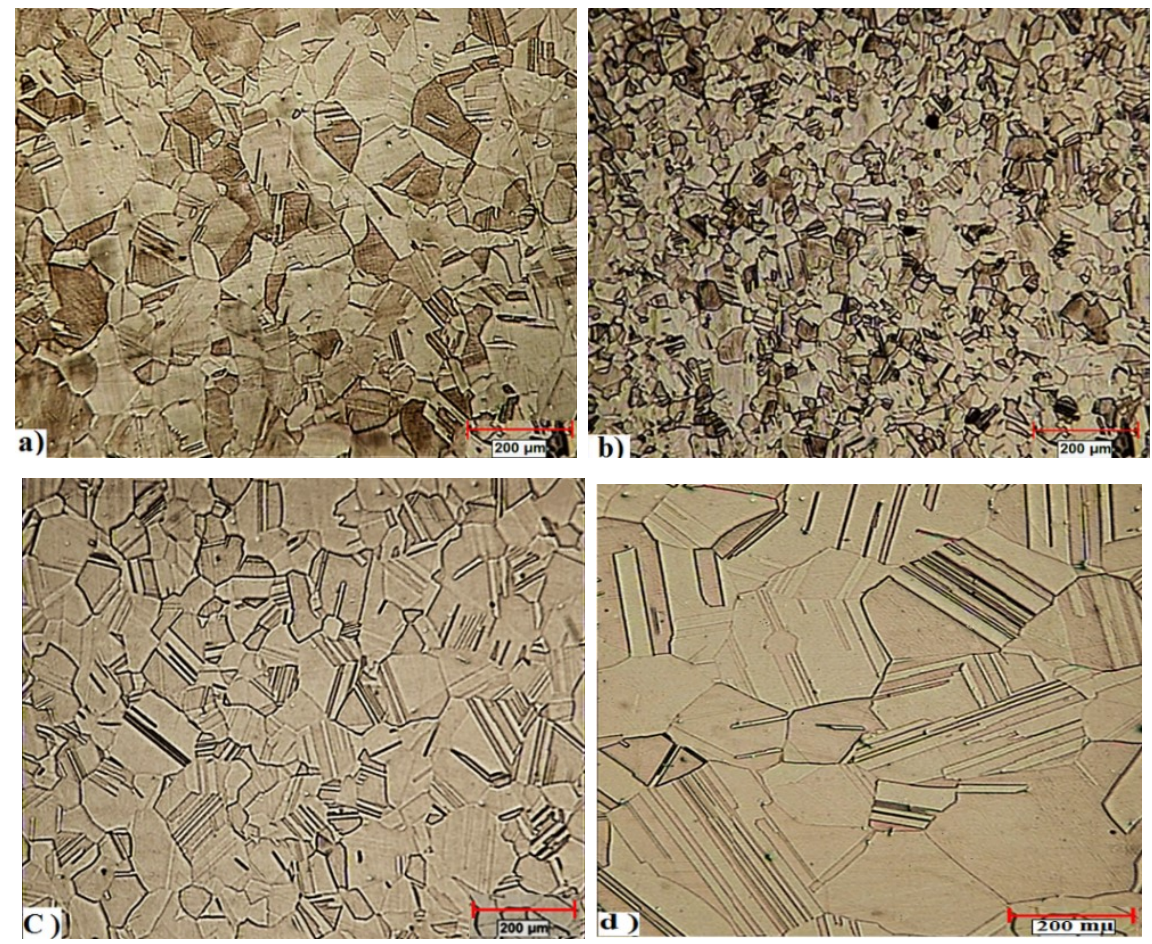

Fig. 1. Optical microscopy images: (a) and (b) 10\% CR, (c) and (d) 30\% CR; after annealing at $1230{ }^{\circ} \mathrm{C}$ for (a) and (c) $20 \mathrm{~min}$, (b) and (d) $30 \mathrm{~min}$. 


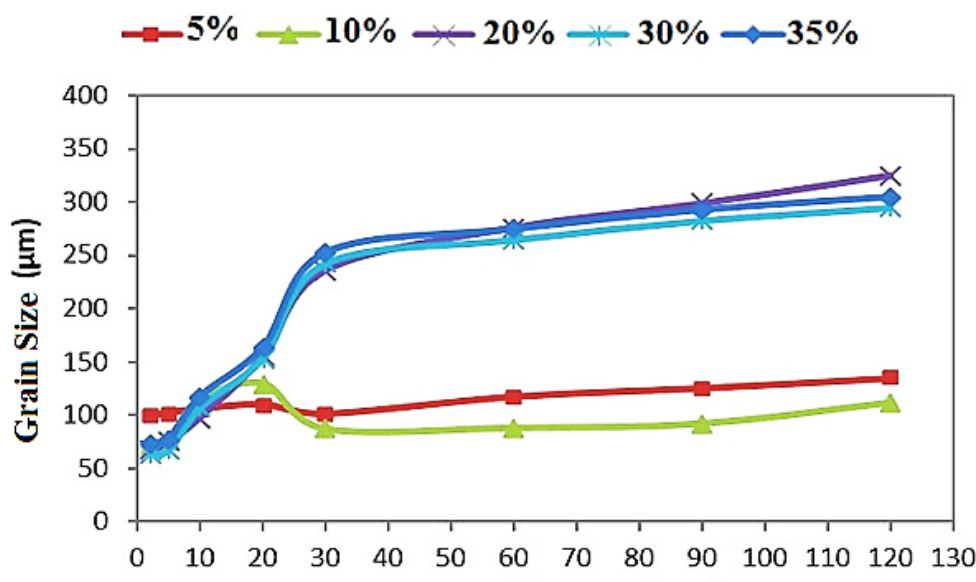

Annealing Time (min)

Fig. 2. The reduction and annealing time effect on the average grain size after annealing at $1230^{\circ} \mathrm{C}$.

\section{Mechanical Properties of Haynes 25 Superalloy}

Hardness

In general, hardness increases with the level of cold-rolling reduction, due to the produced dislocations during cold-working [11]. For instance, after 10, 20 and $30 \%$ thickness reduction, hardness increased from $250 \mathrm{HV}_{30}$ in solution treated sample to 382 $\mathrm{HV}_{30}, 480 \mathrm{HV}_{30}$ and $523 \mathrm{HV}_{30}$, respectively.

Changes in hardness of cold-rolled and annealed samples at $1230{ }^{\circ} \mathrm{C}$ with annealing time are presented in Fig.3. The results show that annealing at $1230^{\circ} \mathrm{C}$ causes a significant drop in hardness due to recovery and possible recrystallization as it has been reported [12]. Recrystallization is usually accompanied by a significant decrease in hardness. After initial decrease in hardness, it increased unexpectedly in $10 \%, 20 \%$ and $30 \%$ cold-rolled samples during annealing between 10 and $30 \mathrm{~min}$; and finally it did not change significantly after $30 \mathrm{~min}$ annealing at $1230{ }^{\circ} \mathrm{C}$. This increase also occurred in 5 and $35 \%$ cold rolled samples. 

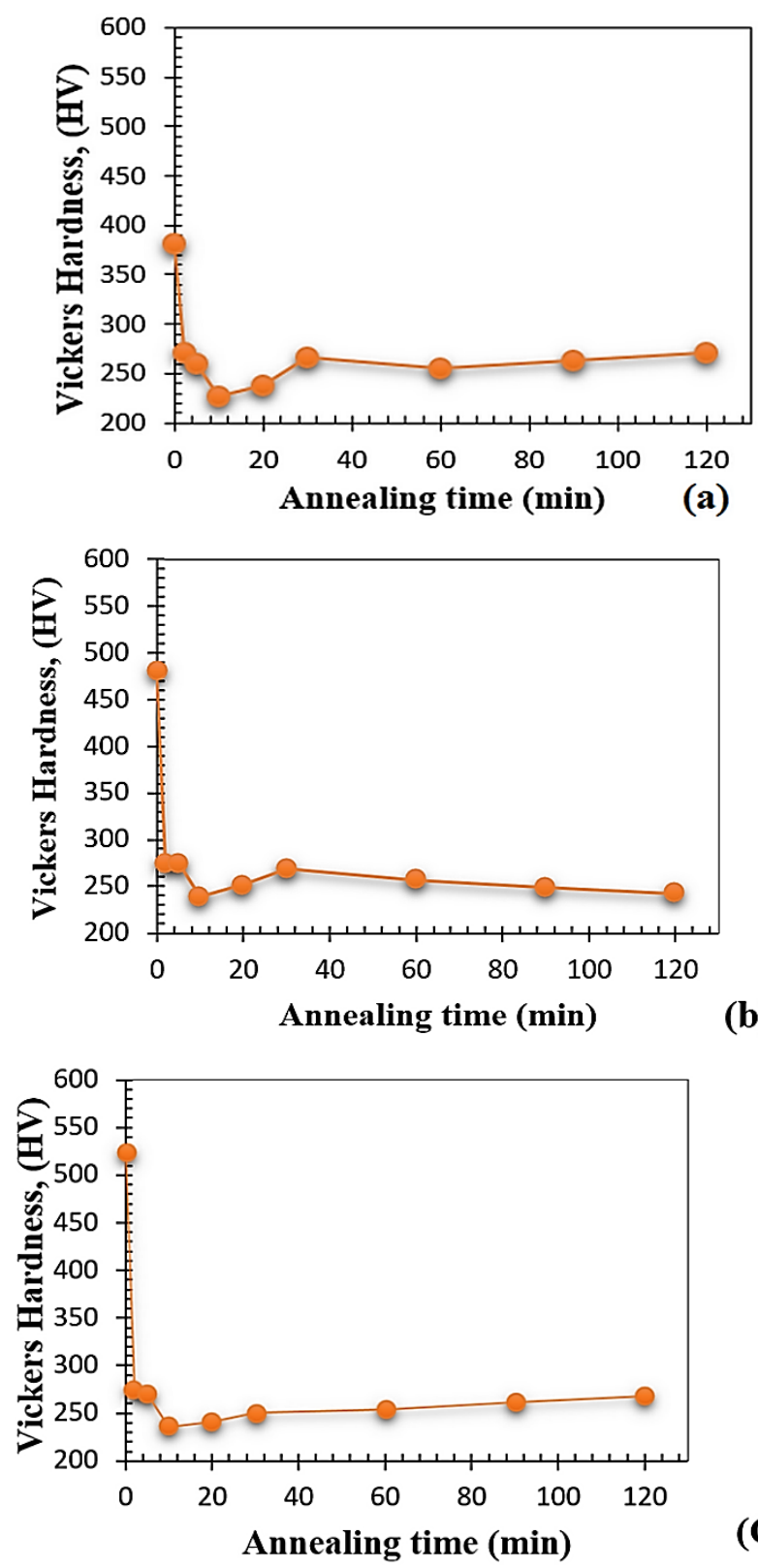

(C)

Fig. 3. Variations of hardness with annealing time for various amounts of cold rolling (a) 10, (b) 20, and (c) $30 \%$. 
This behavior has also been reported by Asgari et al. [13]. According to their founding, the grain size of $35 \%$ cold-worked and heat treated MP35N Ni-Co superalloy samples at $950{ }^{\circ} \mathrm{C}$ for $2 \mathrm{~h}$ did not exhibit remarkable change with increasing time, but the hardness of these samples initially was increased up to $2 \mathrm{~h}$ and then became constant. TEM images of cold-worked samples showed that new hcp phase was formed after annealing at $950{ }^{\circ} \mathrm{C}$.

Moreover, it has been reported $[8,14,15]$ that in Co-Cr-Mo superalloys martensitic transformation after heat treatment of cold-worked alloys can occur so that an hcp phase can be formed in fcc matrix.

According to the results obtained for the hardness in this study, it seems quite possible that for a time period between 10 to $30 \mathrm{~min}$ an hcp phase has formed in fcc matrix of Haynes 25 alloy and resulted to an increase in hardness. In other words, after $10 \mathrm{~min}$, the hardness starts to increase continuously for a time period of approximately 20 min until the induced transformation got nearly saturated and after that the hardness remained relatively constant. Thus, based on the microstructural analysis and hardness results, it can be said that in 5, 10, 20, 30 and $35 \%$ cold-rolled and annealed samples at $1230^{\circ} \mathrm{C}$ for $10-120 \mathrm{~min}$, the new hcp phase was formed.

\section{Tensile tests at room temperature $\left(25^{\circ} \mathrm{C}\right)$}

Fig. 4 shows tensile flow curves of the hot-rolled alloy before and after solution annealing at $1230{ }^{\circ} \mathrm{C}$ for $1 \mathrm{~h}$. Annealing was done in order to increase the ductility, hence improving cold workability of the alloy. After annealing, ductility increased by just over 13\% which was due to the grain growth; the yield strength (YS) and the ultimate tensile strength (UTS) decreased from $665 \mathrm{MPa}$ and $1210 \mathrm{MPa}$ in the hotrolled sample to $406 \mathrm{MPa}$ and $880 \mathrm{MPa}$ in the solution annealed sample. Furthermore, as a consequence of annealing, the average grains size increased from 70 to $154 \mu \mathrm{m}$. This is in agreement with Hall-Petch equation [16] which established the relationship between the strength and grain size. The tensile properties of solution annealed specimen, obtained in this research are significantly similar to the standard strength of Haynes 25 superalloy that has been reported in ASM 5537 (YS= 379-552 MPa, UTS= $896 \mathrm{MPa})$.

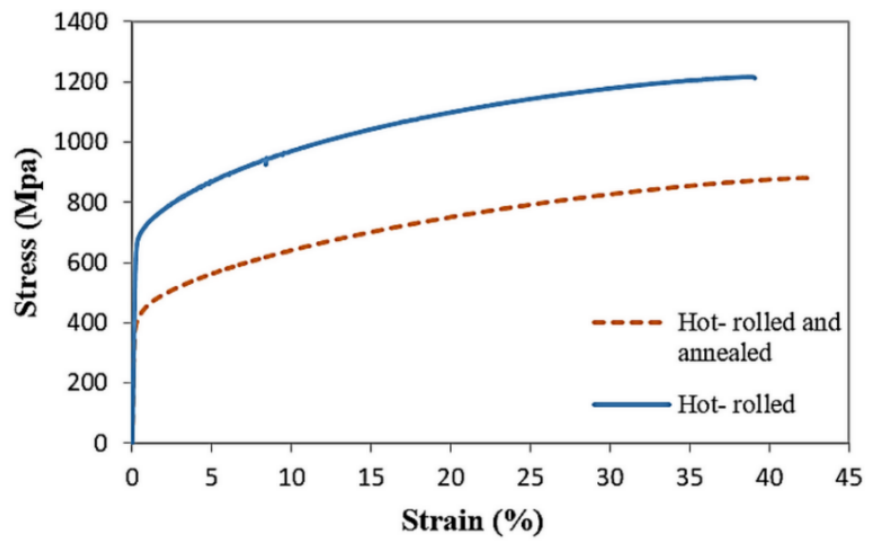

Fig 4. Tensile stress-strain curve of hot-rolled sample before and after annealing at $1230^{\circ} \mathrm{C}$ for $1 \mathrm{~h}$. 
To understand work hardening behavior of the cold-rolled samples and the effect of heat treatment on the tensile properties, the yield stresses of the cold-rolled and annealed samples at $1230{ }^{\circ} \mathrm{C}$ for $30 \mathrm{~min}$, and also the ultimate tensile strengths of both samples are presented in Fig. 5. This figure shows that both YS and the UTS constantly go up with increasing rolling strain. This is evidence for a continues work hardening during cold-rolling process. By increasing the percentage of cold-rolling from 5 to $35 \%$ the YS and the UTS was raised from 432.5 MPa and 946.5 $\mathrm{MPa}$ to $1134 \mathrm{MPa}$ and 1334 $\mathrm{MPa}$ respectively. As shown in Fig. $5 \mathrm{a}$, and $5 \mathrm{~b}$, subsequent to the heat treatment at $1230{ }^{\circ} \mathrm{C}$ for $30 \mathrm{~min}$ the YS and the UTS for all amounts of cold rolled reduction, declined. Such a decrease in strength is mostly caused by reduction in e dislocations density due to recovery, recrystallization and occasionally grain growth [17].
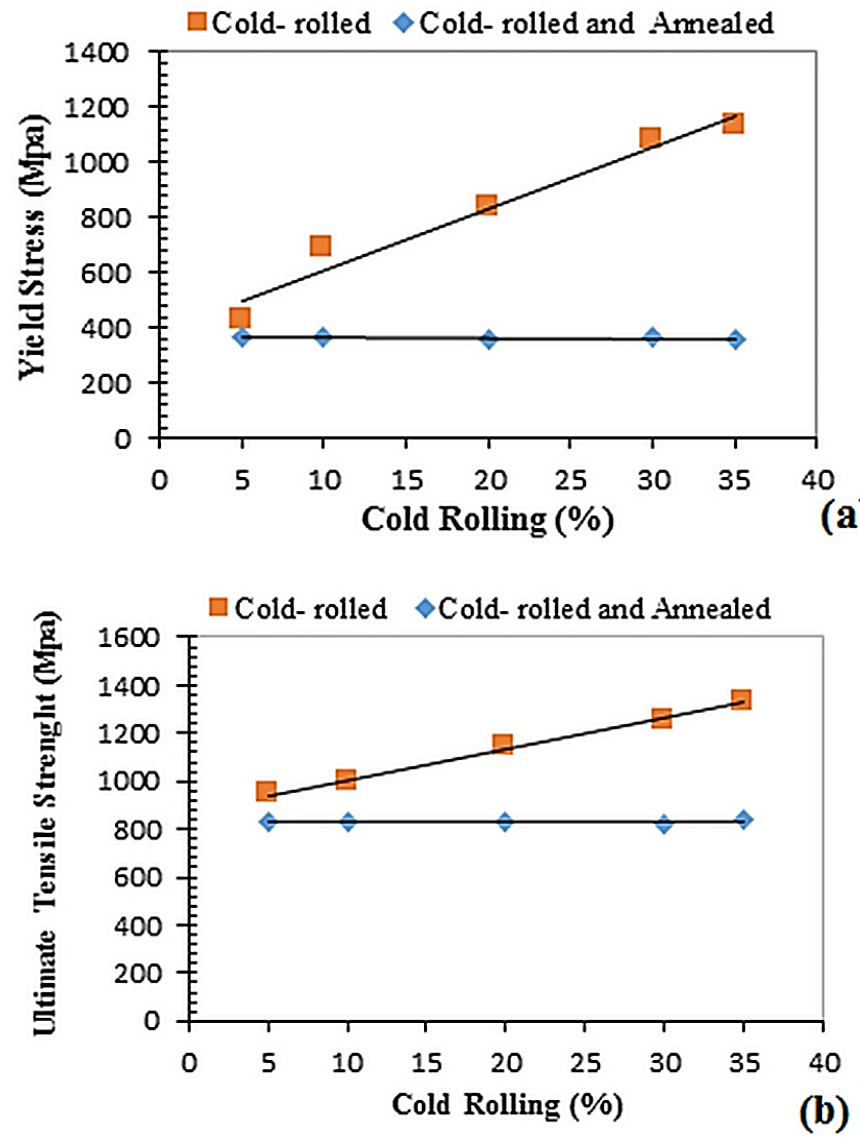

Fig 5. Room-temperature tensile properties of cold rolled and annealed Haynes 25 alloy at $1230{ }^{\circ} \mathrm{C}$ for $30 \mathrm{~min}$; (a) yield strength, (b) ultimate tensile strength.

It was expected that after heating the cold-rolled samples at $1230{ }^{\circ} \mathrm{C}$ for $30 \mathrm{~min}$ the tensile properties of the alloy were improved because of forming a fine microstructure over recrystallization process, particularly, in samples which had already been subjected to a higher percentage of cold-rolling; on the contrary, the YS and the 
UTS initially decreased and then remained approximately stable by increasing the proportion of cold rolling from 5 to $35 \%$.

The tensile strength was not improved probably as a result of high annealing temperature which eliminated the effects of work hardening and stimulated grain coarsening. In 20, 30 and 35\% cold-rolled samples, because of very large reduction in dislocations density after annealing for $30 \mathrm{~min}$ and a higher rate of grain growth, in comparison with 5 and $10 \%$ cold-rolled samples, high decrease of the mechanical properties is understandable.

In samples 5 and $10 \%$ cold-rolled, the effect of work hardening did not completely disappear after annealing at $1230^{\circ} \mathrm{C}$ for $30 \mathrm{~min}$, as shown in Fig. $1 \mathrm{a}$, and b. Probably there is a significant amount of dislocation in these samples comparing to other. In addition, as shown in Fig. 2, the average grain size of 5 and $10 \%$ cold-rolled samples is considerably smaller than the other specimens after annealing for $30 \mathrm{~min}$. Therefore, based on the Taylor's and the Hall-Petch equations [16,18] the YS and the UTS of these samples should be enhanced, but this was not observed (Fig. 5). This behavior of the tensile properties can be attributed to SIMT phenomenon and the formation of the hcp phase in the fcc matrix, according to some literatures [7,8].

According to the research which was carried out by Lee et al. [7] and Koizumi et al. [8], a significant amount of $\gamma$-fcc phase in cobalt-based alloys is maintained as a metastable phase after conventional casting or hot working process, particularly when their composition was not fully stabilized by nickel. Such metastable fcc phase tend to transform to stable $\varepsilon$-hcp phase during plastic deformation at room temperature. Fujita and Ueda [19] studied the formation mechanism of $\varepsilon$-hcp martensite using various TEM techniques, and have reported that the $\varepsilon$-hcp martensite plates stem from overlapping of wide stacking faults. Therefore, it is highly likely that fec to hcp transformation occurred in Haynes 25 alloy.

Additionally, Lee et al. [7] reported that the formation of hcp plates in $\mathrm{Co}-\mathrm{Cr}$ Mo-N alloys, annealed at $1120^{\circ} \mathrm{C}$ for $1 \mathrm{~h}$, has a detrimental impact on tensile properties and the fracture mechanism. The microstructure of these alloys consists of straininduced martensite transformation. Based on TEM observations, the fracture mainly developed at the interface between the $\gamma$-fcc phase and the $\varepsilon$-hcp martensite at annealing twin boundaries [7]. Thus, it was deduced that the annealing twin boundaries act as nucleation sites for SIMT in Co-based alloys. It is also well known that the grain boundaries are suitable sites for martensitic transformations [7]. In addition of cobaltbased alloys, it was indicated that in transformation induced plasticity (TRIP) assisted steels, cracking occurred at the interface between the SIMT phase and ferrite or between the SIMT phases [20]. In the case of non-ferrous alloys, crack or crack-propagation near the strain or stress-induced martensite developed at the grain boundaries [21].

Furthermore, Asgari et al. [13] reported that after ageing of deformed MP35N alloy, a cobalt-nickel superalloy, at $600{ }^{\circ} \mathrm{C}$ for $4 \mathrm{~h}$, solute segregation led to negative values of the stacking fault energy by Suzuki solute segregation to the stacking faults. By widening the SFs, it is highly likely to overlap each other and form $\varepsilon$-hcp plates in the fcc matrix. Additionally, depletion of the matrix from hcp stabilizing elements during the subsequent annealing process, increases the probability of the fcc to hcp transformation. In present research, the presented stress-strain curve, which is an evidence for Suzuki effect in Haynes 25, is in agreement with Asgari's findings. 
The $\varepsilon$-hcp phase deteriorates the mechanical properties. However, being hard this phase increases the wear resistance of the alloy $[7,8]$. In fact, there is a semi-coherent interface between $\gamma$-fcc and $\varepsilon$-hcp phases that can be ruptured easily during plastic deformation $[7,22]$. This semi-coherent interface is associated with numerous atomic lattice misfits which can lead to crack development and fracture in the end. These atomic lattice misfits are mostly presented at the triple junctions which have both grain boundaries and annealing twin boundaries; these boundaries serve as nucleation sites for SIMT. Moreover, it should be noted that in cobalt-based superalloys rupture is mostly launched from $\{111\}$ and $\{0001\}$ planes of fcc and hep structure, respectively [22]. Therefore, based on the above discussion, the strain-induced $\varepsilon$-hcp martensite, which is highly likely to develop at annealing twin boundaries in Haynes 25, can play an important role in declining the yield strength and the ultimate tensile strength in the present research. However, we could not identify these $\varepsilon$-hcp phases by conventional methods.

After annealing the cold-worked materials at $1230{ }^{\circ} \mathrm{C}$ for $30 \mathrm{~min}$, a slight decrease in tensile ductility resulted as shown in Fig. 6. It can be seen that the total elongation decreased moderately with increasing the percentage of cold-rolling. After annealing for $30 \mathrm{~min}$, increase in the average grains size was noticeable starting from 20,30 and 35 cold-rolled samples; therefore, it is expected that ductility rises with enhancing the percentage of cold-rolling and grain growth. However, the elongation decreased by $20 \%$ with the rise of the percentage of cold-rolling from 10 to $35 \%$.

The decreased tensile elongation may be related to the transformation of fcc to hcp phase. As it was mentioned previously, there is a semi-coherent interface between the formed hcp phase and fcc matrix. Part of the coherency strain of this interface is relaxed by creating misfit dislocations; nevertheless, a large strain field still remains there, which can create a barrier for dislocations motion during plastic deformation [23]. Therefore, deformation hardly occurs and consequently the amount of elongation declines.

Decrease in ductility in $20 \%, 30 \%$ and $35 \%$ cold-rolled samples can be also understood by considering the prospect of overlapping stacking faults and annealing twins which increase with increasing the percentage of cold rolling [7,8]. Therefore, there is a strong likelihood that a large amount of hep phase is formed in high strains samples, leading to decrease in ductility. 


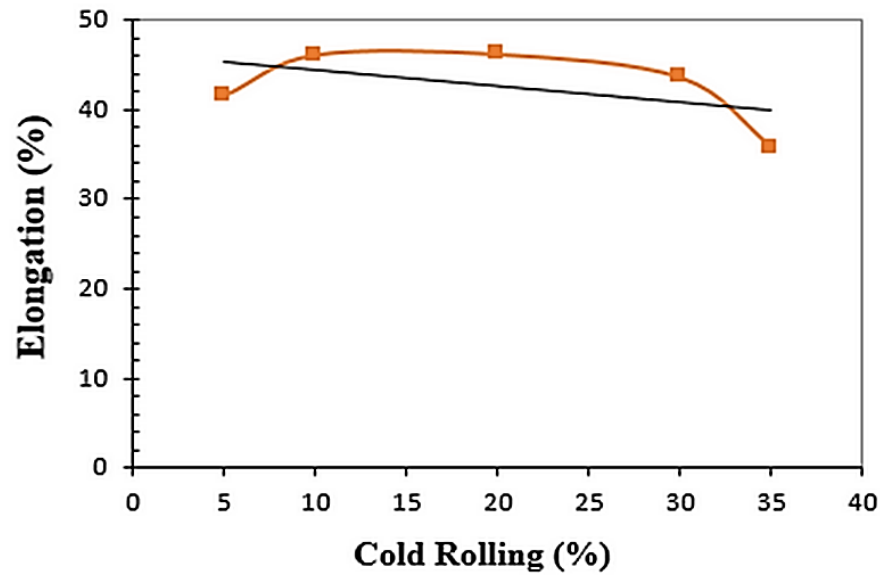

Fig. 6. variations of the total elongation with the percentage of cold rolling after annealing at $1230{ }^{\circ} \mathrm{C}$ for $30 \mathrm{~min}$.

Tensile tests at elevated temperature $\left(760^{\circ} \mathrm{C}\right)$

Tensile tests were conducted at $760{ }^{\circ} \mathrm{C}$. The YS and the UTS of the hot-rolled sample before and after solution annealing at $1230{ }^{\circ} \mathrm{C}$ for $1 \mathrm{~h}$ were measured. When the temperature increased from room temperature to $760{ }^{\circ} \mathrm{C}$, the YS and the UTS were reduced by 37 and $43 \%$, respectively, for the hot-rolled sample before it subjected to solution annealing. For the annealed sample, the YS and the UTS dropped from 406 $\mathrm{MPa}$ and $880 \mathrm{MPa}$ at room temperature to $246 \mathrm{MPa}$ and $479 \mathrm{MPa}$ at $760{ }^{\circ} \mathrm{C}$.

At room temperature deformation, , a small number of slip systems gets active and usually no mechanical twinning occurs during deformation, whereas at elevated temperature both mechanisms of deformation can get active [24]. Furthermore, annealing twins, formed during recrystallization in order to decline the surface energy, contribute to hardening as much as grain boundaries do. So, they are effective barriers to slip and cause an increase in the tensile properties of alloy at room temperature. However, dislocations can pass over annealing twins with cross slip mechanism because of more activation energy at elevated temperature. So that these obstacles will be no longer effective [17,24]. In this way, the YS and the UTS suddenly drop at $760{ }^{\circ} \mathrm{C}$.

Fig. 7 shows the tensile properties of the all cold-rolled specimens (at $760{ }^{\circ} \mathrm{C}$ ), after annealing at $1230{ }^{\circ} \mathrm{C}$ for $30 \mathrm{~min}$. As it can be seen, the YS and the UTS experienced a steady trend similar to the room-temperature tensile properties. The YS and the UTS declined by $7 \%$ and just over $22 \%$ with increasing the percentage of cold rolling from 5 to $35 \%$. Loss of the tensile properties at $760^{\circ} \mathrm{C}$ is significantly high than at room temperature since the semi-coherent interface between $\varepsilon$-hcp and $\gamma$-fcc is more unstable at $760{ }^{\circ} \mathrm{C}[17]$.

Changes in elongation with the percentage of cold rolling at $760{ }^{\circ} \mathrm{C}$ are presented in Fig. 8. The total elongation decreased by decreasing of the percentage of cold rolling. 


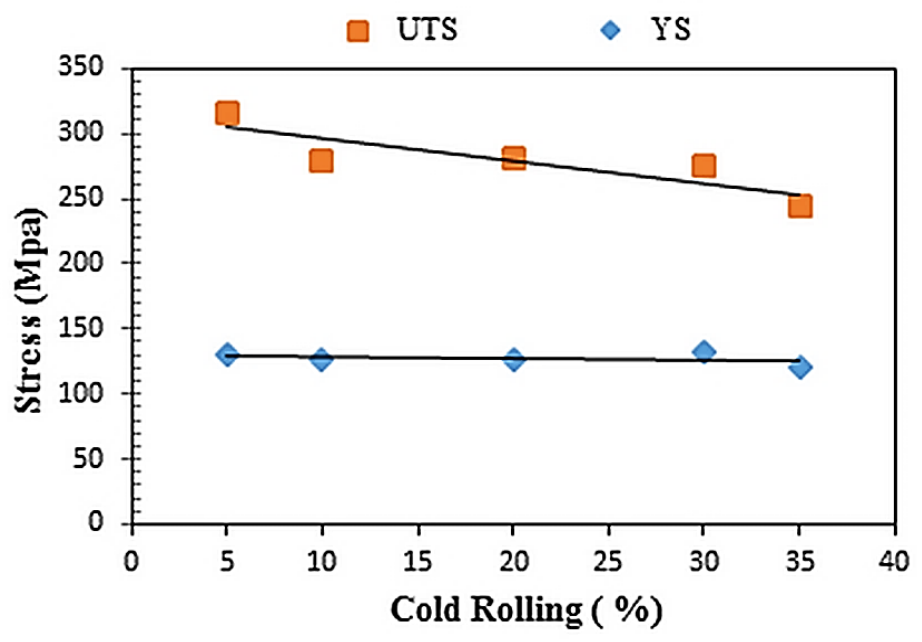

Fig. 7. High temperature $\left(760^{\circ} \mathrm{C}\right)$ tensile properties of cold rolled and annealed Haynes 25 alloy at $1230^{\circ} \mathrm{C}$ for $30 \mathrm{~min}$.

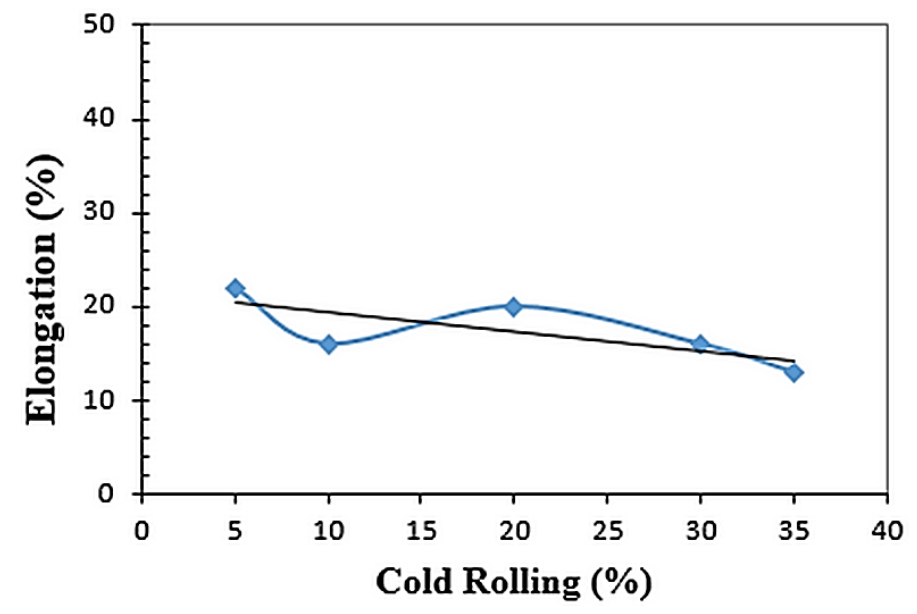

Fig. 8. Variations of the elongation with the percentage of cold rolling at high temperature after annealing at $1230^{\circ} \mathrm{C}$ for $30 \mathrm{~min}$.

Fig. 9 shows tensile stress-strain curves of 5 and $20 \%$ cold-rolled samples after annealing at $1230{ }^{\circ} \mathrm{C}$ for $30 \mathrm{~min}$. The results show that two types of serrations were presented within the temperature of $1230{ }^{\circ} \mathrm{C}$. The first type is regular, continuous and appeared mostly in initial amounts of strain. Second type is irregular with sudden drop in high amounts of strain. 


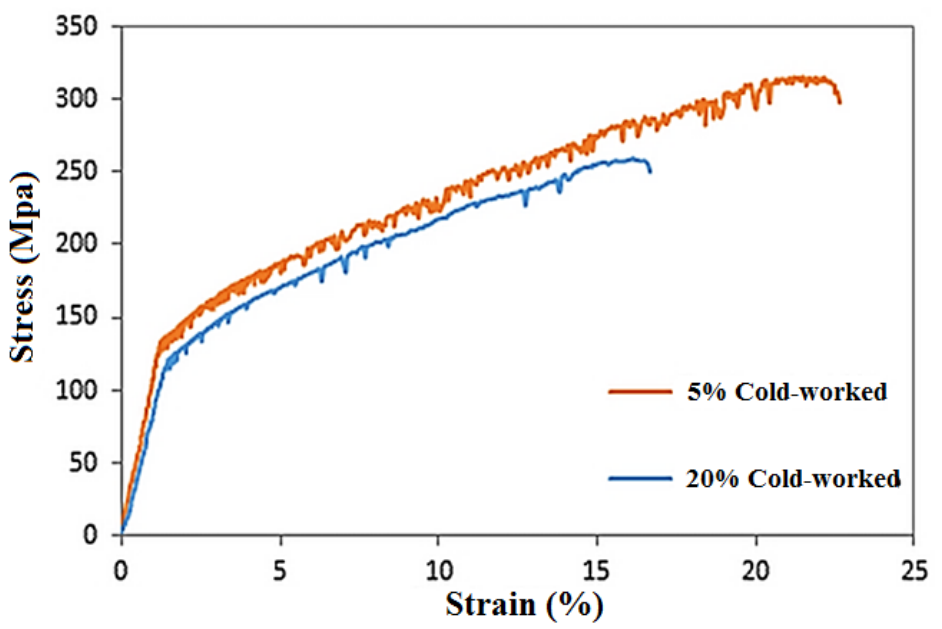

Fig. 9: Tensile stress-strain curve was obtained from the tensile test at $760{ }^{\circ} \mathrm{C}$ for 5 and $20 \%$ cold-rolled samples after annealing at $1230^{\circ} \mathrm{C}$ for $30 \mathrm{~min}$.

In the articles by Asgari et al. [13] and Wang et al. [25] on Haynes 25 and Mg$\mathrm{Nd}-\mathrm{Zn}$ alloy respectively, the authors have attributed serrated flow to Suzuki effect that causes solute atoms segregation to stacking faults. Haynes 25 superalloy contains $\mathrm{Cr}$ and $\mathrm{W}$ that stabilize hep phase [1]. During annealing, $\mathrm{W}$ and $\mathrm{Cr}$ prefer to segregate into stacking faults to low SFE. The stacking faults are widened, which increases the superalloy strength with forming atomic atmosphere around partial dislocations and pinning them, but the number of solute atoms must meet the effective pinning demands. Therefore, the process lasts some time. Following this, by exerting more stress, dislocations suddenly leave the atmosphere in some cases and stress decreases rapidly with the mobile dislocations, getting free from solutes atmosphere. However, because of high temperature and consequently high diffusion, Suzuki effect can occur repetitively $[13,25]$. This mechanism results in creating the first type of serration in the tensile stress-strain curve.

Once the $\varepsilon$-hcp phase forms in $\gamma$-fcc structure, SFE declines. This reduction in SFE stimulates increase in stacking faults density. As a result, the prospect of overlapping of stacking faults on $\{111\}$ planes increases and it is more likely to form mechanical twins during deformation [17]. Moreover, low SFE results in more difficult sliding during deformation [26]. Hence, because of insufficient slip systems mechanical twins are probably created and more deformation comes about. In such manner, the formation of the mechanical twins can be a reason for appearing second type of serration in stress-strain curve.

As shown in Fig. 9, the number of serrations in 5\% cold-rolled sample is relatively higher than $20 \%$ cold-rolled sample which may be the consequence of higher dislocations density. 


\section{Conclusions}

1) By increasing the amount of deformation from 10 to $30 \%$, the lower initial time is needed to finish the recrystallization at $1230{ }^{\circ} \mathrm{C}$. Increasing the annealing time from 20 to 30 min resulted in grain coarsening in 30\% coldrolled sample. However, in $10 \%$ cold-rolled sample, the average grain size decreased by $33 \%$ over this period of time. Moreover, the rate of grain growth remained approximately stable for all cold-rolled samples in the time range from 30 to 120 min that can be explained in terms of Zener pinning of grain boundaries.

2) In 20,30 and $35 \%$ cold-rolled samples, after annealing at $1230{ }^{\circ} \mathrm{C}$, the hardness was not affected by grain growth in the range of from 30 to $120 \mathrm{~min}$ and in spite of grain coarsening it is increased in the range from 20 to 120 min. The main cause of the increase in hardness can be related to the formation of $\varepsilon_{6}$ - hcp phase in the $\gamma$ - fcc matrix in heated cold-worked alloy.

3) After annealing at $1230{ }^{\circ} \mathrm{C}$ for $30 \mathrm{~min}$, by increasing the percentage of cold rolling both the yield strength and the ultimate tensile strength at room temperature and $760{ }^{\circ} \mathrm{C}$ firstly declined and then remained relatively stable. This can be related to SIMT phenomenon. In fact, grain boundaries and annealing twin boundaries act as nucleation sites for SIMT development during cold working. By formation of $\varepsilon$-hcp phase, crack nucleation and propagation can occur along the interface between the fcc and the hep phases; therefore, tensile properties decrease.

4) The total elongation of the cold-rolled specimens after annealing at $1230{ }^{\circ} \mathrm{C}$ for 30 min decreased by $20 \%$ with increasing the percentage of cold-rolling from 10 to $35 \%$ at room temperature. It is due to existence of the strain fields at the semi-coherent interface between $\varepsilon$-hcp and $\gamma$-fcc phases that create a barrier to dislocations motion and thus deformation hardly occurs.

\section{Acknowledgement}

The authors would like to thank Mr. Hasan Badri (Metallic Materials Research Center (MMRC-MA), Tehran, Iran) for the help in the experimental work.

\section{References}

[1] G.D. Sandrock, L. Leonard: National Aeronautics and Space Administration (NASA), 1966 August. P. Report No.: ND-3528.

[2] J. Favre, Y. Koizumi, A. Chiba, D. Fabregue, E. Maire: Metall Mater Trans A, 44 (2013) 2819-2830.

[3] D.L. Klastrom: J Mater Eng Perform, 2 (1993) 523-530

[4] C.T. Sims: JOM - J Min Met Mat S, 2 (1969) 27-42.

[5] J. Teague, E. Cerreta, M. Stout: Metall Mater Trans A, 35A (2004) 2767.

[6] Azom, Superalloy Haynes 25, http://www.azom.com/article.aspx?ArticleID=7788, Accessed 19 Nov 2012.

[7] B. Lee, H. Matsumoto, A. Chiba: Mater Lett, 65 (2011) 843-846.

[8] Y. Koizumi,S. Suzuki, K. Yamanaka,B.S. Lee, K. Sato, Y. Li, S. Kurosu, $\underline{H}$. Matsumoto, A. Chiba: Acta Mater, 61 (2013) 1648-1661.

[9] H.M. Tawancy, V.R. Ishwar, B. E. Lewis: J Mater Sci Lett, 5 (1986) 337-341.

[10] K. Song, M. Aindow: Mater Sci Eng A-Struct, 479 (2008) 365-372. 
[11] H.C. Lin, S.K. Wu, T.S. Chou , H.P. Kao: Acta Metall Mater, 39 (1991) 20692080.

[12] S. Kalpakjian, S.R. Schmid: Manufacturing Process for Engineering Materials, $5^{\text {th }}$ Edition, Addison Wesley Longman, Inc., California, 1997, 1040.

[13] S. Asgari, E. El-Danaf, E. Shaji E, S.R. Kalidindi, R.D. Doherty: Acta Met, 46 (1998) 5795-5806.

[14] K. Yamanaka, M. Mori, Y. Koizumi, A. Chibaet: J Mech Behav Biomed Mater, 32 (2014) 52-61.

[15] H. Tawancy, V. Ishwar, B. Lewis: Mater Lett, 5 (1986) 337-341.

[16] L. Murr: Metall Trans A, 6 (1975) 505-513.

[17] A. Rollett, F. Humphreys, G.S. Rohrer, M. Hatherly: Recrystallization and Related Annealing Phenomena, 2nd Edition, Elsevier, The United Kingdom, 2004, 215 267.

[18] G.I. Taylor: The Mechanism of Plastic Deformation of Crystals, Royal Society, London, 1934, 362-387.

[19] H. Fujita, S. Ueda: Acta Met, 20 (1972) 759-767.

[20] G. Lacroix, T. Pardoen, P.J. Dacques: Acta Met, 56 (2008) 3900.

[21] G.Z. Wang, F.Z. Xuan, S.T. Tu,Z.D. Wang: Mater Sci Eng, A527 (2010) 1529.

[22] S. J. Lee, Y. K. Lee, A. Soon, Appl Surf Sci, 258 (2012) 9977-9981.

[23] D.A. Porter, K.E. Easterling: Phase Transformations in Metals and Alloys, 3rd Edition, Chapman \& Hall, New York, 1992.

[24] L. Remy: Metall. Trans A, 12 (1981) 387-408.

[25] W.H. Wang, D. Wu, S.S.A. Shah, R.S. Chen, C.S. Lou: Mater Sci Eng A, 649 (2016) 214-221.

[26] M. Kenzevic, J.S. Carpenter, Manuel. L. Lovato, R.J. McCabe: Acta Met, 63 (2014) 162-168. 